\title{
Understanding the dynamic of greenspace in the urbanized area of Beijing based on high resolution satellite images
}

\author{
Yuguo Qian, Weiqi Zhou*, Weifeng Li, Lijian Han \\ State Key Laboratory of Urban and Region Ecology, Research Centre for Eco-Environmental Sciences, Chinese Academy of Sciences, Shuangqinglu 18, \\ Haidian District, Beijing 100085, China
}

\section{A R T I C L E I N F O}

\section{Keywords:}

Beijing

Greenspace dynamics

Greenspace pattern

High resolution satellite images

Scale

Urban

\begin{abstract}
A B S T R A C T
Urban greenspace plays an essential role in urban ecosystem and highly contributes to the welfare of urban residents. Understanding the dynamics of greenspace is crucial for its planning and management. Previous studies have largely focused on changes in greenspace in urbanizing regions, using medium resolution remotely sensed data. However, the changes of greenspace in urbanized areas need to be accurately quantified based on high spatial resolution images because they are directly related to human health and well-being. This paper aims to enhance the understanding on dynamics of greenspace within well-developed areas of the city, using Beijing City, China as a case study. Using high spatial resolution remotely sensed imagery, we analyzed the spatial pattern of greenspace and its change on two scales: (1) the entire area within the 5 th ring road, and (2) in 4 belts from urban center to fringe. We found urban greenspace was very dynamic. The proportion of urban greenspace increased by $5.45 \%$, or $36.3 \mathrm{~km}^{2}$ in size from 2005 to 2009 . The amounts of gain and loss of greenspace were $69 \mathrm{~km}^{2}$ and $32.7 \mathrm{~km}^{2}$, respectively, or $10.36 \%$ and $4.91 \%$ of the entire study area. Because of the very limited lands for greening in urbanized areas, the new patches of greenspace were generally small, with the mean patch size of $676.31 \mathrm{~m}^{2}$. However, those small patches enhanced the connectivity and continuity of urban greenspace. In addition, we found the differences in configuration of greenspace patches across the 4 belts were greater than the differences in total percent cover, indicating that compared to percent coverage, greenspace configuration may be more influenced by the development age.
\end{abstract}

(c) 2014 Elsevier GmbH. All rights reserved.

\section{Introduction}

Rapid urbanization has greatly changed urban greenspace (Zhou and Wang, 2011), and consequently affected its functions. Understanding the dynamics of urban greenspace is crucial for urban greenspace planning and management. Greenspace in urban area is closely connected with human health, well-being, and social safety (Groenewegen et al., 2006). The presence of greenspace can purify polluted air (Yang et al., 2005; Nowak et al., 2006), alleviate urban heat island (Zhou et al., 2011a; Li et al., 2013), protect water from non-point source pollution (Conine et al., 2004), and maintain biodiversity (Attwell, 2000; Dwivedi et al., 2009). It also provides considerable socioeconomic benefits (Geoghegan et al., 1997; Gobster and Westphal, 2004).

Numerous studies have investigated the changes in urban greenspace. Most of the studies have used remotely sensed data

\footnotetext{
* Corresponding author. Tel.: +86 01062849268.

E-mail addresses: Guozigu1015@gmail.com (Y. Qian),wzhou@rcees.ac.cn (W.Zhou), li.wf@rcees.ac.cn (W. Li), ljhan@rcees.ac.cn (L. Han).
}

with medium spatial resolution such as Landsat Thematic Mapper (TM) images to quantify the spatial pattern of urban greenspace and its changes (Hurd et al., 2001; Seto et al., 2002; Yuan et al., 2005; Kong and Nakagoshi, 2006; Zhou and Wang, 2011; Miller, 2012; Portillo-Quintero et al., 2012). These studies have shown that greenspace was very dynamic on the urban fringe. In particular, urban expansion has led to great loss of urban greenspace (Seto et al., 2002; Yuan et al., 2005; Portillo-Quintero et al., 2012), as well as greenspace fragmentation (Hurd et al., 2001; Miller, 2012). In contrast, changes in urban greenspace tended to be ignored in more intensively urbanized locations (Zhou et al., 2011b).

With the importance of urban greenspace increasingly recognized, more and more efforts have been dedicated to increase urban greenspace (Li et al., 2004; Beijing Landscape Bureau, 2007; Van Den Hoek et al., 2014). This is particularly true in many Chinese cities such as Beijing, which now face serious environmental issues, in spite of the desire of the general public for high quality environment with the increased welfare (Yang et al., 2005; Yu et al., 2005). Meanwhile, cities are still facing great pressure from development due to economic and population growth. Therefore, we hypothesize urban 

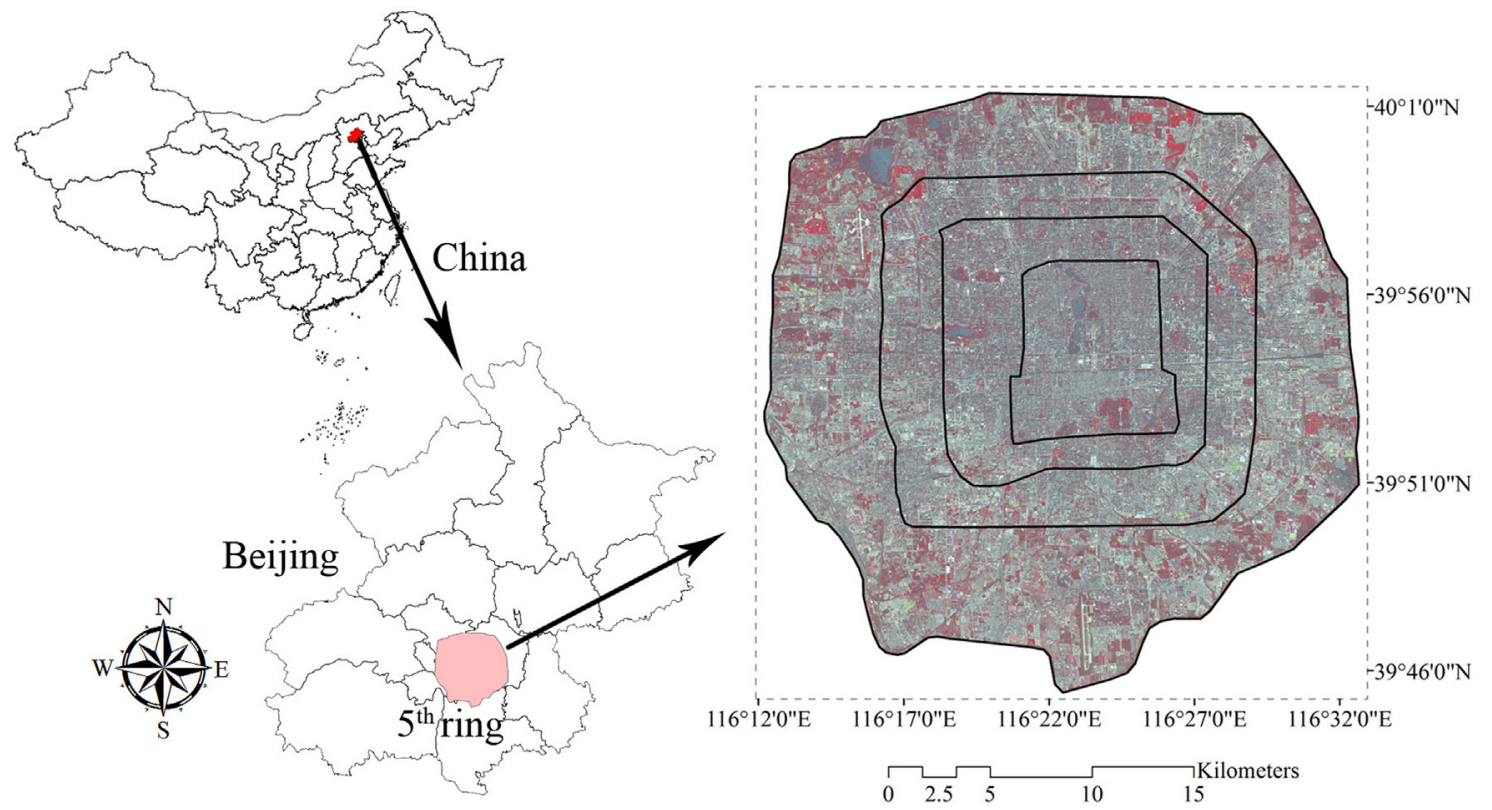

Fig. 1. The study area: the region within the 5th ring road of Beijing, China.

greenspace in well-developed city regions may be experiencing great changes, even over a very short time period because of the combination of pressure in development and increasing efforts being taken to increase urban greenspace in many cities.

Using Beijing as a case study, we aim to test this hypothesis by quantifying the spatial-temporal dynamics of urban greenspace in the most developed area of Beijing City, that is, the area within the 5th ring road. We used high spatial resolution image data to map urban greenspace. This is because urban greenspace is highly fragmented, and many of the patches are quite small (Zhou et al., 2011b). Images with medium resolution are inadequate to depict the dynamics of greenspace at the fine scale within urbanized areas. Greenspaces were mapped for 2005 and 2009, using an objectbased approach. The spatial pattern of greenspace and its change were analyzed at two scales: (1) the entire area within the 5th ring road, and (2) in 4 belts from the urban center to the fringe, namely the areas within the 2nd ring road, and between the 2nd and 3rd ring road, 3rd-4th ring road and 4th-5th ring road, respectively. In addition, the spatial patterns of greenspace gained and of greenspace lost were analyzed separately.

\section{Study area}

Beijing, the capital of China, is located in the northeast of the North China Plain (longitude: $115^{\circ} 25^{\prime}-117^{\circ} 30^{\prime}$ E, latitude $39^{\circ} 28^{\prime}-41^{\circ} 25^{\prime} \mathrm{N}$; Fig. 1). It has a total area of approximately $16,410 \mathrm{~km}^{2}$; roughly $38 \%$ is flat and $62 \%$ is mountainous. The city has a history of more than 3000 years, and has been as the capital for more than 800 years. Since the implementation of the Reform and Open Policy in 1978, Beijing has undergone dramatic economic and population growth. The total population increased by $137 \%$ from 8.72 million in 1978 to 20.69 million in 2012, and the percentage of the urban population increased from $55 \%$ to $86 \%$ (Beijing Municipal Statistical Bureau, 2013). The gross domestic product (GDP) also increased rapidly from 10.88 billion RMB in 1978 to 1787.94 billion RMB in 2012 (Beijing Municipal Statistical Bureau, 2013). Along with this rapid socioeconomic development was the fast expansion of Beijing city, and the increasing efforts being taken to increase the urban greenspace in the city (Beijing Landscape Bureau, 2007).

We chose the study area within the 5th ring road of Beijing City, a well-developed area (Fig. 1). Inside the study area, there

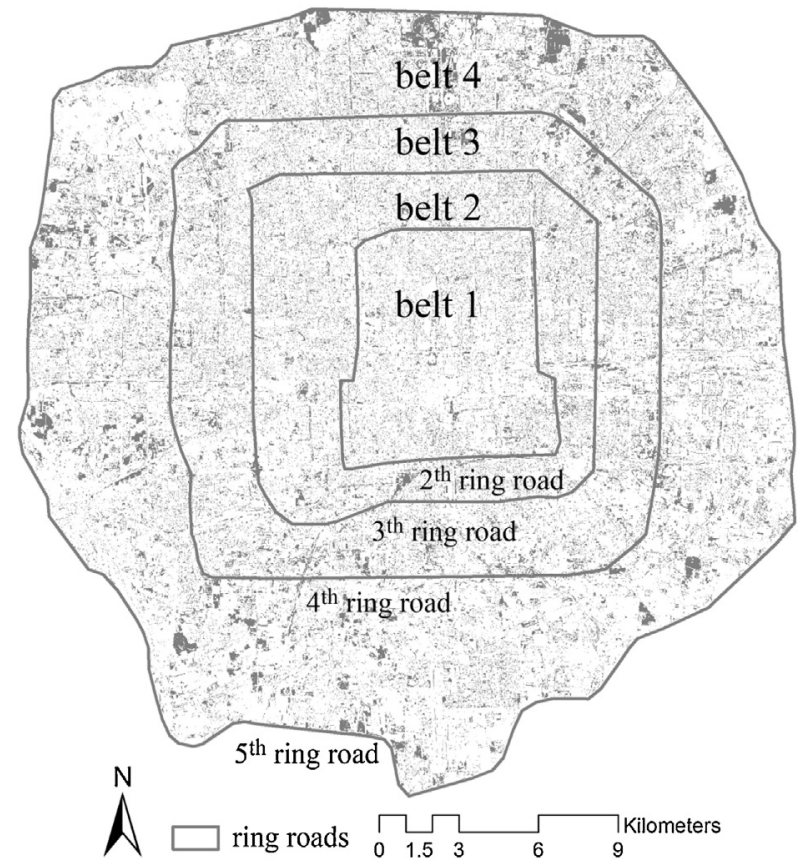

Fig. 2. The layout of four belts inside the 5 th ring road.

are 4 ring roads concentrically arranged from the urban center to the fringe, namely the $2 \mathrm{nd}$, the $3 \mathrm{rd}$, the 4 th and the 5 th ring road which were built in 1992, 1999, 2001 and 2003, respectively (Fig. 2). The areas within each of the ring roads were $62.1 \mathrm{~km}^{2}, 158.2 \mathrm{~km}^{2}$, $301.9 \mathrm{~km}^{2}$ and $666 \mathrm{~km}^{2}$, respectively, from the 2 nd to the 5 th ring road. Land cover in the study area was dominated by impervious surfaces and vegetation. Most of the agricultural land occurred in the urban fringe.

\section{Materials and methods}

\section{Image data preprocessing}

We used SPOT-5 (Systeme Probatoire d'Observation dela Tarre) image acquired on October 8, 2005 and ALOS (Advanced Land 
Table 1

Landscape metrics used in this study.

\begin{tabular}{|c|c|c|c|}
\hline Metrics & Description & Unit & Range \\
\hline Percentage of landscape (PLAND) & $\begin{array}{l}\text { The proportion of the area of certain land use } \\
\text { class to the entire landscape area }\end{array}$ & $\%$ & $0<$ PLAN $\leq 100$ \\
\hline Patch density (PD) & The number of patches per 100 ha & Number per 100 ha & $\mathrm{PD}>0$ \\
\hline Mean patch size (MPS) & $\begin{array}{l}\text { The area occupied by a particular patch type } \\
\text { divided by the number of patches of that type }\end{array}$ & $\mathrm{m}^{2}$ & MPS $>0$, no limit \\
\hline Landscape shape index (LSI) & $\begin{array}{l}\text { Patch perimeter divided by the minimum } \\
\text { perimeter possible for a maximally compact } \\
\text { patch of the corresponding patch area }\end{array}$ & None & $\mathrm{LSI} \geq 1$ \\
\hline
\end{tabular}

Observation Satellite) image acquired on October 22, 2009 to map greenspace in the study area. The image of SPOT-5 has one panchromatic band with $2.5 \mathrm{~m}$ spatial resolution, and four multispectral bands including three $10 \mathrm{~m}$ resolution bands (green, red, near-infrared) and one $20 \mathrm{~m}$ resolution shortwave infrared band. Similarly, the image of ALOS has one panchromatic band and four multispectral bands, with spatial resolution of $2.5 \mathrm{~m}$ and $10 \mathrm{~m}$, respectively. To take the advantage of both high spatial resolution and multispectral features, we pan-sharpened the multispectral bands using the panchromatic band from the same image, using the principal components algorithm. Consequently, we obtained multispectral image with $2.5 \mathrm{~m}$ spatial resolution. We did this separately for SPOT and ALOS images. We then conducted geometric registration using imagery from Google $\mathrm{e}^{\mathrm{TM}}$ as the reference map. We used the second-order polynomial model and the nearest neighborhood resampling approach for spatial rectification. The root mean square error was less than 0.5 pixel. A vector layer data of the ring roads of Beijing city was also used in the greenspace pattern analyses.

\section{Classification and accuracy assessment}

We identified five land cover types for the study area, including vegetation, impervious surface, farmland, bare soil and water. Vegetation included grass and trees, which referred to as urban greenspace. Farmland included lands covered by crops, fallow lands and greenhouses. Bare soil referred to lands under-construction and with no vegetation cover. Impervious surface were mainly roads and building roofs. Water mostly occurred in lakes, rivers and irrigated farmlands.

We used an object-based approach for land cover classification (Zhou and Troy, 2009). An object-based approach first segments image into objects which are then assigned to a land cover class. An object-based approach is superior to traditional pixel-based classification, especially when using high spatial resolution images (Gao and Mas, 2008). For example, an object-based approach can largely avoid the "salt-and-pepper" effect frequently found in pixel-based classification. We conducted the accuracy assessment separately for the two classification maps. For each map, three hundred random points were created using a stratified random sampling method in Erdas Imagine (version 9.1). The "true" land cover type of each of these random points was visually interpreted by referring to the historical high spatial resolution images in Google Earth. The overall accuracies of classifications for 2005 and 2009 were $92.58 \%$ and $94.12 \%$, respectively. The accuracies of vegetation were $95.4 \%$ and $96.1 \%$, respectively.

\section{Quantify the spatial pattern of urban greenspace}

We selected four landscape metrics to describe the greenspace pattern, including percentage of landscape (PLAND), patch density (PD), mean patch size (MPS) and landscape shape index (LSI) (Table 1), which were calculated in ArcGIS (McGarigal et al., 2002). We used the PLAND to quantify the abundance of greenspace, and the three other metrics to describe the patch characters of greenspace.

With the landscape metrics, we analyzed the urban greenspace at two scales, (1) the entire study area, and (2) the four belts divided by two neighboring ring roads (Fig. 2). These four belts represent the gradual development stages of Beijing, from the old urban center of belt 1 to the recently developed urban fringe of belt 4 . For the entire study area, we first conducted synthetic analysis of landscape pattern in 2005 and 2009, and then calculated the land cover transfer matrix to analyze the conversions among land cover types. We further quantified the configuration of the greenspace, and its dynamics. At the finer scale, we analyzed the spatial pattern of greenspace and its change for each belt, and compared their differences among the four belts.

\section{Change detection and analysis on greenspace}

Changes in greenspace included vegetation gain and loss from 2005 to 2009. We extracted the gained greenspace by identifying patches changed from non-vegetation to vegetation. Patches transferred from vegetation to non-vegetation were classified as lost greenspace. Following, we compared the percentage and patch characters of the two directions of change using four landscape metrics at two scales. These two directions of changes reflected the actual dynamics of greenspace, and revealed the distribution of the changed patches.

\section{Results}

Spatial pattern of urban greenspace and its dynamic: Analysis for the entire study area

Greenspace was one of the dominant land cover types in the study area (Fig. 3; Table 2). More importantly, urban greenspace was highly dynamic. Percent cover of urban greenspace was $22.57 \%$ in 2005 , and increased to $28.01 \%$ in 2009 , an increase of $5.45 \%$, or $36.3 \mathrm{~km}^{2}$ in 4 years. In fact, among all the four types of land cover, the change in percent cover of greenspace was the largest.

Table 2

Percent cover of each of the 5 land cover types in 2005 and 2009.

\begin{tabular}{|c|c|c|c|c|c|}
\hline & Farmland (\%) & Impervious surface (\%) & Bare soil (\%) & Vegetation (\%) & Water (\%) \\
\hline 2005 & 6.62 & 68.39 & 0.98 & 22.57 & 1.44 \\
\hline 2009 & 4.79 & 64.18 & 1.43 & 28.01 & 1.59 \\
\hline
\end{tabular}



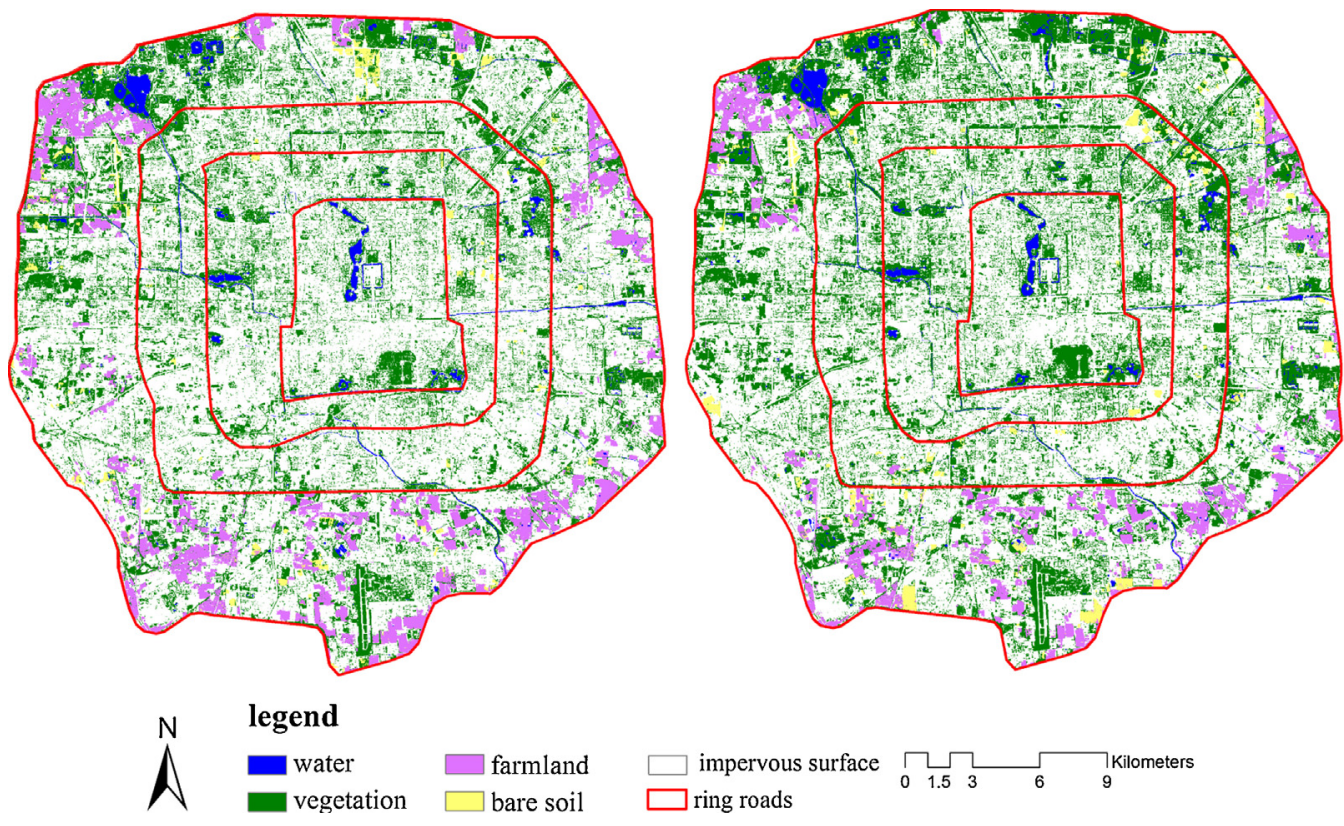

Fig. 3. Land cover classifications in 2005 (a) and 2009 (b).

Table 3

The land cover transfer matrix from 2005 to 2009.

\begin{tabular}{|c|c|c|c|c|c|}
\hline & Farmland (\%) & Impervious surface (\%) & Bare soil (\%) & Vegetation (\%) & Water (\%) \\
\hline Farmland & 72.09 & 9.16 & 3.10 & 15.26 & 0.40 \\
\hline Impervious surface & 0.02 & 85.68 & 1.03 & 13.13 & 0.14 \\
\hline Bare soil & 0.16 & 50.86 & 15.79 & 31.48 & 1.71 \\
\hline Vegetation & 0.00 & 19.54 & 1.56 & 78.25 & 0.65 \\
\hline Water & 0.00 & 4.68 & 0.96 & 3.77 & 90.59 \\
\hline
\end{tabular}

"New" urban greenspace mostly occurred in lands previously covered by impervious surfaces (Table 4). Approximately $13 \%$ of the impervious surfaces in 2005 were converted to greenspace, accounting for $89.82 \%$ of the new urban greenspace (Tables 3 and 4 ). A small proportion of the new urban greenspace was gained from bare soil and farmland.

While the total percent cover of greenspace largely increased from 2005 to 2009, a significant proportion of greenspace was converted to other land cover types, mostly impervious surfaces. Approximately $20 \%$ of the urban greenspace in 2005 , or $30.1 \mathrm{~km}^{2}$ was converted to imprevious surfaces (Table 3 ). Very small proportions of urban greenspace were converted to bare soil and water from 2005 to 2009 (Table 3).

Patch density increased slightly from $95 \mathrm{~km}^{-2}$ in 2005 to $96 \mathrm{~km}^{-2}$ in 2009. In contrast, there was a relatively large increase in the mean patch size from $2385 \mathrm{~m}^{2}$ to $2909 \mathrm{~m}^{2}$. The slight increase of patch density but relatively large increase in mean patch size, indicated that urban greenspace became more continuous, rather than being further fragmented. The LSI declined from 327.63 to 297.48 , which suggested greenspace patches became more compact. The distributions of patch area showed that most patches were relatively small (Fig. 7 ). A total of $74.2 \%$ of the patches in 2005 , and $76.7 \%$ in 2009 were smaller than $900 \mathrm{~m}^{2}$, the size of a single pixel of the most commonly used $30 \mathrm{~m}$ spatial resolution

Table 4

Percentages of different land cover types converted to greenspace.

\begin{tabular}{lllll}
\hline & Farmland (\%) & $\begin{array}{l}\text { Impervious } \\
\text { surface (\%) }\end{array}$ & Bare soil (\%) & Water (\%) \\
\hline Vegetation & 0.01 & 89.82 & 7.19 & 2.98 \\
\hline
\end{tabular}

TM data. To readily recognize a land cover object, it shall be greater than 4 times of the size of a pixel (Lillesand et al., 2004), that is, $3600 \mathrm{~m}^{2}$ for TM data. But $92 \%$ of the patches in 2005 (or $19.2 \%$ of the total area of greenspace) and $91.9 \%$ (or $13.3 \%$ of the total area of greenspace) in 2009 were smaller than $3600 \mathrm{~m}^{2}$ (Fig. 7).

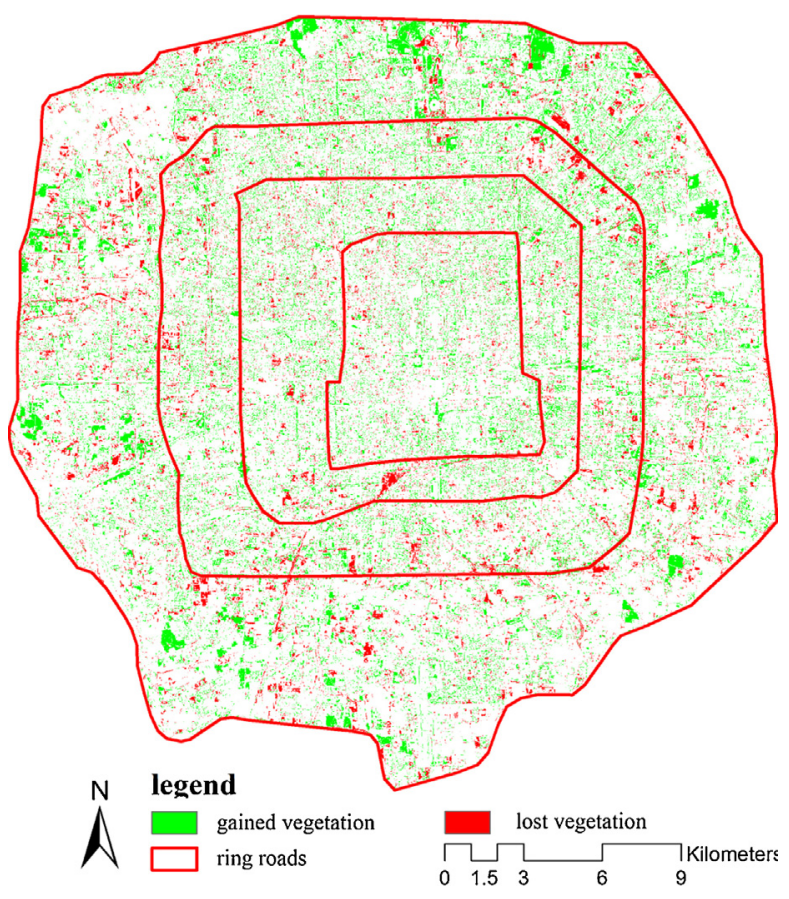

Fig. 4. The vegetation dynamic from 2005 to 2009. 

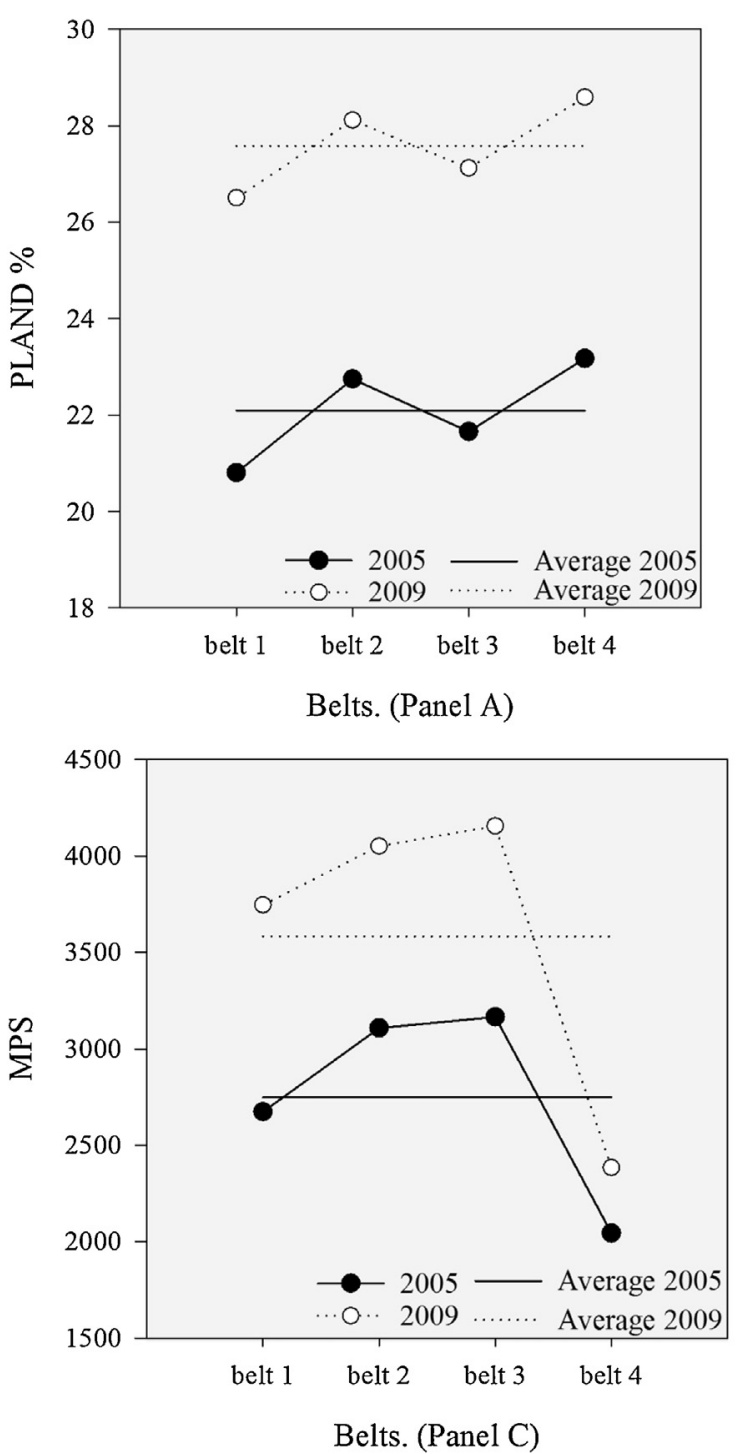
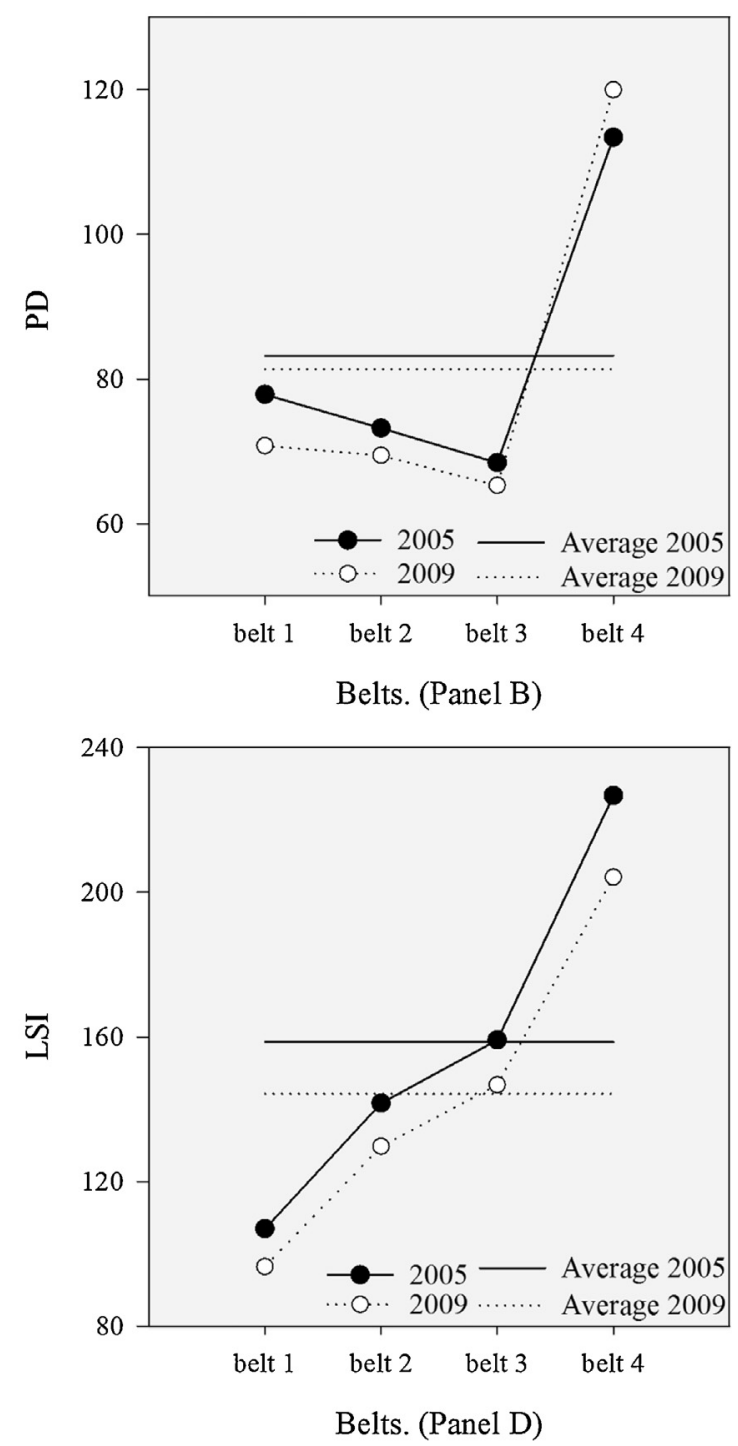

Fig. 5. The percent cover (Panel A), patch density (Panel B), mean patch size (Panel C), and landscape shape index (Panel D) of greenspace in the four belts.

We found the proportions of greenspace gain and loss were $10.36 \%$ and $4.91 \%$, or 69 and $32.7 \mathrm{~km}^{2}$, respectively, leading to a net increase of $5.45 \%$, or $36.3 \mathrm{~km}^{2}$ (Fig. 4; Table 6). Changes of gain and loss in urban greenspace were more intense than suggested by percentage of net increase. While both new and lost patches of greenspace occurred across the entire study area, patches with relatively large sizes tended to appear in the urban fringe. The number of new patches was almost twice that of lost patches. In addition, the mean size of new patches was larger than that of lost patches. But sizes of most of the new and lost patches were quite small. $85.5 \%$ of the new patches and $89.2 \%$ of the lost patches were smaller than $900 \mathrm{~m}^{2}$, accounting for $27.2 \%$ and $31 \%$ of the total areas of gained and lost greenspace, respectively (Tables 5 and 6; Fig. 8). These patches may be not readily detected by using TM data. The landscape shape index of new patches was also greater than that of lost patches, suggesting increased complexity.

Table 5

Metrics for urban greenspace in the overall 5th ring.

\begin{tabular}{lllll}
\hline & PLAND (\%) & PD & MPS & LSI \\
\hline 2005 & 22.57 & 95 & 2385.39 & 327.63 \\
2009 & 28.01 & 96 & 2908.67 & 297.48 \\
\hline
\end{tabular}

Spatial pattern of urban greenspace and its dynamic: Analysis by different zones/belts

For both time slices, percent cover of greenspace was the lowest in belt 1 , the urban core area, and the highest in belt 4 , the urban fringe. Percent cover of greenspace was slightly higher in belt 2 than that in belt 3 (Fig. 5, panel A). The percent cover differences between belt 1 and belt 4 were diminished from $2.37 \%$ in 2005 to $2.08 \%$ in 2009. From 2005 to 2009, percent cover of greenspace in each belt, however, significantly increased. For example, percent cover of greenspace in belt 1 increased from $20.8 \%$ in 2005 to $26.5 \%$ in 2009 , an increase of $5.7 \%$, or 353.9 ha.

From 2005 to 2009, patch density in each belt remained largely unchanged, while mean patch size in each belt significantly increased (Fig. 5, Panel C). Patch density decreased slightly from belt 1 to belt 3, but increased sharply in belt 4 (Fig. 5, Panel B). In

Table 6

Metrics of gained and lost greenspace in the study area.

\begin{tabular}{lcrll}
\hline 2005-2009 & PLAND (\%) & PD & MPS & LSI \\
\hline Gained greenspace & 10.36 & 153 & 676.31 & 436.26 \\
Lost greenspace & 4.91 & 85 & 577.63 & 298.79 \\
\hline
\end{tabular}



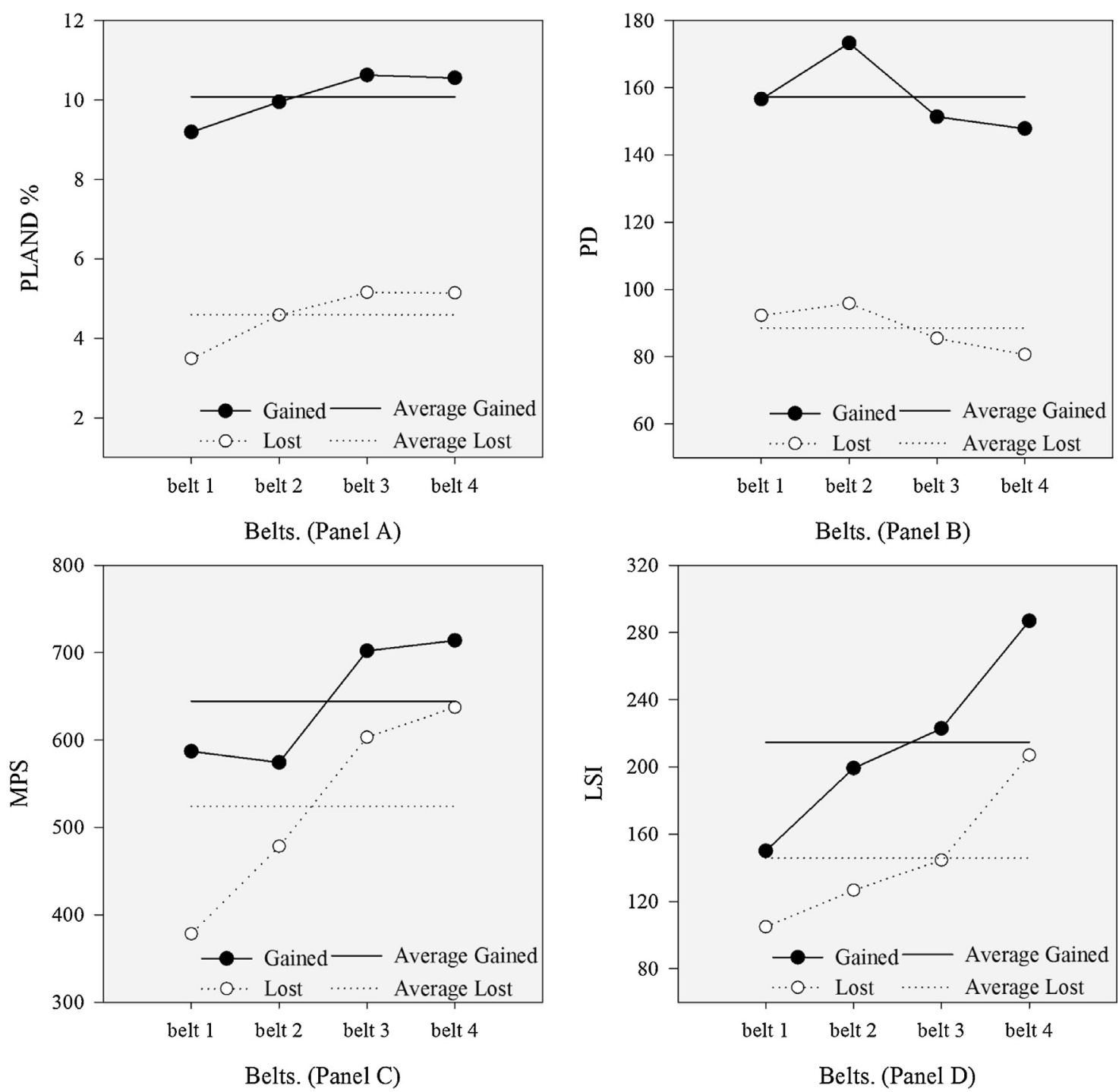

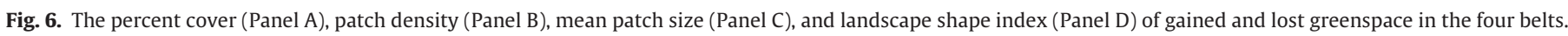

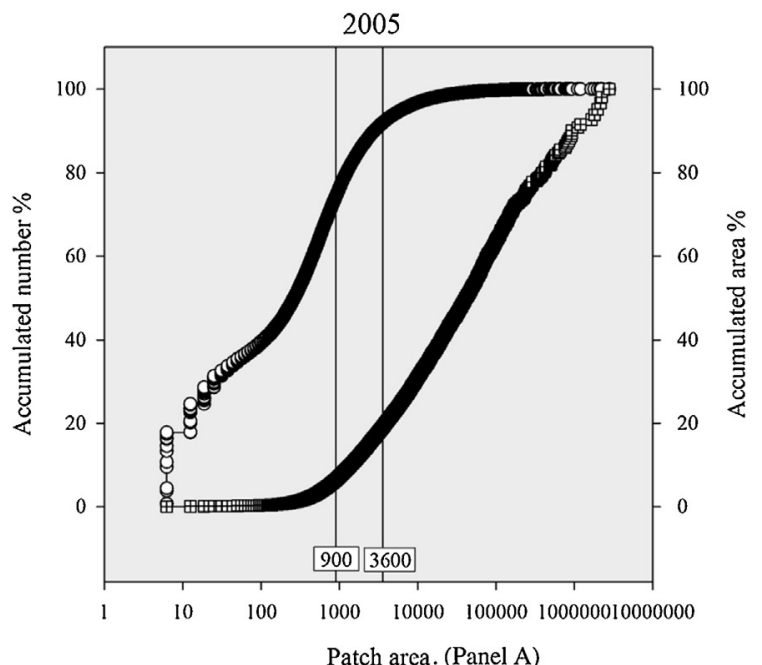

Patch area. (Panel A)

$-\infty$ - Accumulated number $\%$ 巴- Accumulated area \%

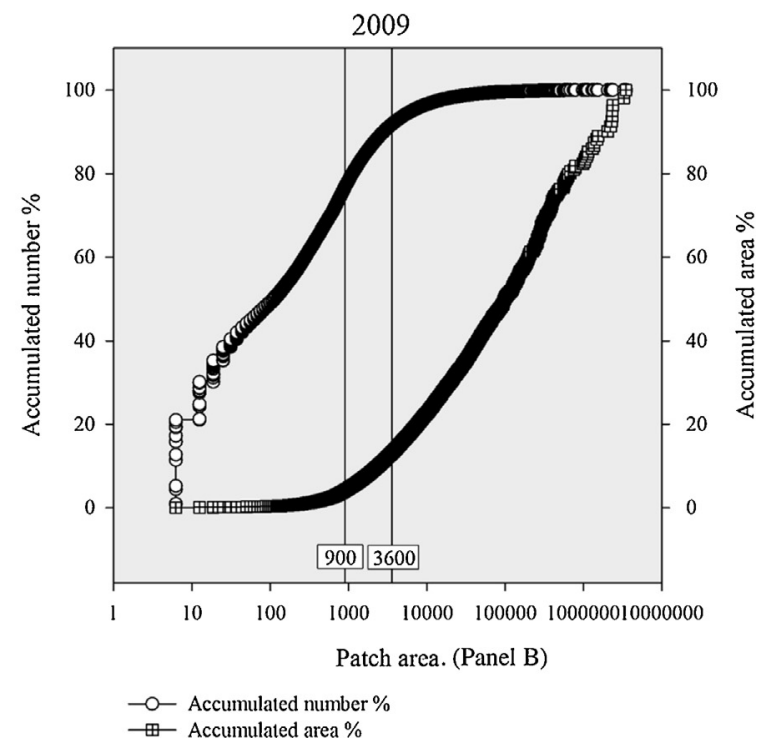

$\longrightarrow$ - Accumulated number $\%$
$\rightarrow$ Accumulated area $\%$

Fig. 7. Distribution of patches according to patch size in 2005 (Panel A) and 2009 (Panel B). 

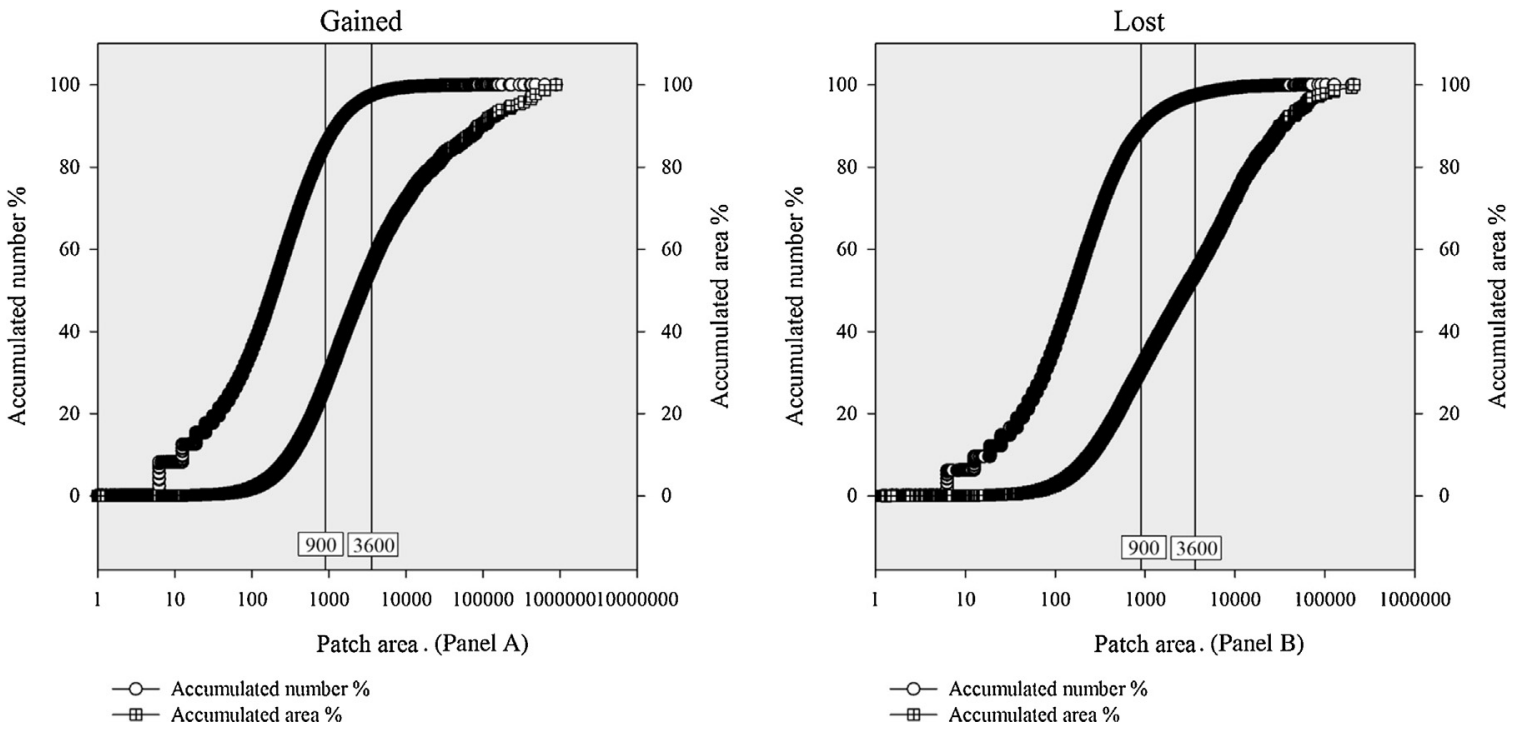

Fig. 8. Distribution of gained patches (Panel A) and lost patches (Panel B), according to patch size.

contrast, the mean patch size first increased from belt 1 to belt 3 , then significantly decreased in belt 4 . The decreased patch density and increased mean patch size from belt 1 to belt 3 indicated that the greenspace patches in these belts became smaller in number and larger in size. In contrast, the reverse trends of patch density and mean patch size in belt 4 suggested that patches of greenspace became more fragmented in the urban fringe. The landscape shape index slightly decreased in each belt from 2005 to 2009. The patch shape of greenspace became more complex from the belt 1 to belt 4 in the two time slices, indicating more complex patch shape in the urban fringe (Fig. 5, Panel D). In the relatively old developed area from belt 1 to belt 3, the percent cover and patch characters of greenspace were similar. However, in the youngest developed area of belt 4 , the greenspace patches were more fragmented and complex than the old ones.

Changes in percent cover of greenspace, both gained and lost, increased from belt 1 to belt 4 , suggesting increasing dynamics from the urban core to fringe (Fig. 6, Panel A). There was a declining trend in changes in patch density of gained and lost greenspace from belt 1 to belt 4 , but belt 2 had the highest patch density (Fig. 6, Panel B). The changed greenspace patches had largest mean patch size in belt 4 , and continuously decreased from the outside belt to the inside (Fig. 6, Panel B). The patch shape index for gained and lost greenspace patches increased from the urban core to the fringe, suggesting the increased complexity in patch shape of changed greenspace.

\section{Discussion}

We found urban greenspace within the 5th ring road, the well-urbanized region of Beijing City, was very dynamic, and experienced evident increase from 2005 to 2009. The increase in urban greenspace in Beijing from 2005 to 2009 was largely due to the great efforts in increasing urban greenspace by the local government, particularly for the 2008 Beijing Olympic Games. The government invested 300 billion CNY (or approximately $\$ 50$ billion) to establish the Olympic Forest Park, to plant trees along roads, and implement the "Plant Where Possible" (Jian Feng Cha Lv) policy. This result contradicts those from many of the previous studies, which suggested that urban greenspace remained largely unchanged, or tended to decline within the built-up areas (Chen et al., 2001; Li et al., 2011; Xu et al., 2011). This inconsistency may be largely due to the use of data with different spatial resolutions when mapping urban greenspace and its changes. Many of the previous studies used relatively low resolution data to map urban greenspace. Consequently, these studies failed to map most of the small patches of greenspace that constitute a significant proportion of greenspace in highly urbanized areas. These small patches of urban greenspace can only be extracted by high resolution images, as done in this study. In fact, the changed greenspace patches were typically small. The mean patch size was $676 \mathrm{~m}^{2}$ for gained greenspace and $578 \mathrm{~m}^{2}$ for the lost patches. That means, when using TM data, with the pixel area of $900 \mathrm{~m}^{2}$, many changes cannot be detected, especially for the isolated ones. In addition, those small greenspaces, mostly located in residential areas and along streets, may directly benefit the local residents (Kemperman and Timmermans, 2014) and contribute to biodiversity, such as birds (Strohbach et al., 2013). These results underscore the importance of the use of the high spatial resolution image data in urban greenspace monitoring and management.

We found that most of the new patches of greenspace regenerated from lands previously covered by impervious surfaces. This result is different from many of the previous studies (He et al., 2001; Zhou and Wang, 2011), in which urban greenspace was found to be continuously encroached and fragmented by impervious surfaces. This is partly because many of the previous studies focused on newly urbanizing regions, instead of well-developed areas. In the urban core of Beijing, the implementation of the "Plant Where Possible" policy has led to the creation of many of the small patches of new urban greenspace. In addition, the redevelopment also tends to increase urban greenspace. In the urban fringe, the establishment of park and redevelopment on previous "urban village" also led to increase of urban greenspace. These new patches of urban greenspace generally occurred in lands previously covered by impervious surfaces.

In addition, those new patches enhanced the connectivity and continuity of urban greenspace. In the entire study area, the mean patch size of greenspace became larger, while the patch density, or total number of patches remained largely unchanged. These results indicated that urban greenspace became more continuous, rather than fragmented during the process of urbanization. The increase of greenspace cover and enhanced connectivity may be potentially beneficial for species maintenance (Fahrig, 2003) and mitigatigation of urban heat islands (Li et al., 2012).

The most recently developed area, belt 4 , had the highest percent cover of greenspace, but the differences in percent cover between belt 4 and the other belts were not substaintial. For 
example, percent cover of urban greenspace in belt 4 was only only $0.43 \%$ higher than that in belt 2 for 2005 , and $0.47 \%$ for 2009 . However, the configuration metrics of greensapce in belt 4 were significantly different from those from the other belts. Generally, patches in belt 4 were larger in number, but smaller in size.

Changes in coverage of greenspace, as well as its spatial pattern, may have significant impacts on the functioning of the greenspace in urbanized area. For example, the net increase of $36.3 \mathrm{~km}^{2}$ greenspace, mostly converted from previously impervious surfaces, will have significant mitigation effects on the urban heat island effect in Beijing (Zhou et al., 2011a; Li et al., 2012). In addition, the increased size of greenspace patches may further contribute to the decrease of land surface temperature (Zhou et al., 2011a, 2014; Li et al., 2012). Consequently, local residents suffer less from diseases caused by high temperature (Kenney et al., 2014; Sun et al., 2014), and may also consume less energy to maintain a comfortable indoor temperature. The increase in greenspace and change in spatial configuration may also have significant impacts on urban biodiversity (Kong et al., 2010), stream biotic conditions (Shandas and Alberti, 2009), and air quality (Nowak et al., 2006; Nowak et al., 2014).

The change analysis that included the gain and loss of greenspace revealed that the actual changes in percent cover of greenspace were much larger than the net increase, since the lost greenspace was compensated by gained greenspace. Whether the ecological values of lost greenspace could also be compensated by new ones, however, remains unknown. In addition, while the change analysis provided important insights, we did not quantitatively analyze the relationships between the greenspace with changes (i.e., new or lost) and the previously existing ones. For example, how many gained patches of greenspace were expanded from existing ones, and how many greenspace patches were totally removed, or partially removed. This type of analysis can provide more information on dynamics of greenspace, and therefore deserves further investigation.

\section{Conclusion}

This study analyzed the changing greenspace pattern in the well-developed area of Beijing, China from 2005 to 2009, using high resolution satellite images. We found that greenspace in the study area has increased by approximately $37 \mathrm{~km}^{2}$ within 4 years, an annual increase of more than $9 \mathrm{~km}^{2}$. Most of the "new" greenspace were regenerated from lands previously covered by impervious surfaces. The increase in urban greenspace was largely due to the great efforts in increasing urban greenspace by the local government, particularly for the 2008 Beijing Olympic Games. These efforts not only led to increase of greenspace coverage, but also to changes in spatial configuration of greenspace. While the patch density remained largely unchanged, the mean size of patches increased from $2385 \mathrm{~m}^{2}$ to $2909 \mathrm{~m}^{2}$. It is worth noting there was a loss of urban greenspace due to urban development, even though there was a net increase in urban greenspace.

The spatial distribution of urban greenspace varied from the urban core to the fringe. While the percent cover of greenspace was similar across the four belts from the urban core to the fringe, their configuration was different. Greenspace in the urban fringe was more fragmented, likely due to the higher intensity of development. Our results also underscore the importance of the use of high resolution data in quantifying the fine-scale dynamics of urban greenspace. We found changes (gain or loss) to patches of greenspace tended to be small. The average size of patches was $676 \mathrm{~m}^{2}$ for gained greenspace, and $578 \mathrm{~m}^{2}$ for the lost patches. These types of changes were only detectable by high spatial resolution data, but not by frequently used medium resolution image data. This study expanded our understanding of the dynamics of urban greenspace in the context of China's rapid urbanization. Understanding of the changing greenspace pattern is crucial for decision makers to evaluate the human living environment and make appropriate policies for urban sustainability.

\section{Acknowledgements}

The support of the National Natural Science Foundation of China (Grant No. 41371197) and the "One hundred talents" program of Chinese Academy of Sciences is gratefully acknowledged. This research was also supported by National Key Technology R\&D Program of China during the Twelfth Five-Year Plan Period (2012BAC13B01). The authors would like to thank the editor and the anonymous reviewers for their helpful comments and suggestions. Comments from Dr. Steward Pickett improved the early draft of this manuscript.

\section{References}

Attwell, K., 2000. Urban land resources and urban planting - case studies from Denmark. Landscape Urban Plann. 52, 145-163.

Beijing Landscape Bureau, 2007. Beijing Green Space Planning. Beijing Landscape Bureau, Beijing (in Chinese).

Beijing Municipal Statistical Bureau, 2013. Beijing Statistical Yearbook. China Statistics Press, Beijing (in Chinese)

Chen, Y., Li, P., Shi, X., Zhou, H., 2001. Estimating vegetation coverage change using remote sensing data in Haidian district, Beijing. Acta Phytoecol. Sin. 5, 012.

Conine, A., Xiang, W.-N., Young, J., Whitley, D., 2004. Planning for multi-purpose greenways in Concord, North Carolina. Landscape Urban Plann. 68, 271-287.

Dwivedi, P., Rathore, C.S., Dubey, Y., 2009. Ecological benefits of urban forestry: the case of Kerwa Forest Area (KFA), Bhopal, India. Appl. Geogr. 29, 194-200.

Fahrig, L., 2003. Effects of habitat fragmentation on biodiversity. Annu. Rev. Ecol., Evol. Syst. 34, 487-515.

Gao, Y., Mas, J.F., 2008. A comparison of the performance of pixel based and object based classifications over images with various spatial resolutions. Online J. Earth Sci. 2, 27-35.

Geoghegan, J., Wainger, L.A., Bockstael, N.E., 1997. Spatial landscape indices in a hedonic framework: an ecological economics analysis using GIS. Ecol. Econ. 23, 251-264.

Gobster, P.H., Westphal, L.M., 2004. The human dimensions of urban greenways: planning for recreation and related experiences. Landscape Urban Plann. 68, 147-165.

Groenewegen, P.P., van den Berg, A.E., de Vries, S., Verheij, R.A., 2006. Vitamin G: effects of green space on health, well-being, and social safety. BMC Public Health 6, 149.

He, C., Shi, P., Chen, J., Zhou, Y., 2001. A study on land use/cover change in Beijing area. Geogr. Res. 20, 679-687.

Hurd, J.D., Wilson, E.H., Lammey, S.G., Civco, D.L., 2001. Characterization of forest fragmentation and urban sprawl using time sequential Landsat imagery. In: ASPRS 2001 Annual Convention, St. Louis, MO.

Kemperman, A., Timmermans, H., 2014. Green spaces in the direct living environment and social contacts of the aging population. Landscape Urban Plann. 129, 44-54.

Kenney, W.L., Craighead, D.H., Alexander, L.M., 2014. Heat waves, aging, and human cardiovascular health. Med. Sci. Sports Exerc. 46, 1891-1899.

Kong, F., Nakagoshi, N., 2006. Spatial-temporal gradient analysis of urban green spaces in Jinan, China. Landscape Urban Plann. 78, 147-164.

Kong, F., Yin, H., Nakagoshi, N., Zong, Y., 2010. Urban green space network development for biodiversity conservation: identification based on graph theory and gravity modeling. Landscape Urban Plann. 95, 16-27.

Li, F., Wang, R., Paulussen, J., 2004. A study on ecological concept planning of urban greenspace in Beijing. Urban Plann. Forum, 014.

Li, M., Zhu, Z., Vogelmann, J.E., Xu, D., Wen, W., Liu, A., 2011. Characterizing fragmentation of the collective forests in southern China from multitemporal Landsat imagery: a case study from Kecheng district of Zhejiang province. Appl. Geogr. 31, 1026-1035.

Li, X., Zhou, W., Ouyang, Z., 2013. Relationship between land surface temperature and spatial pattern of greenspace: what are the effects of spatial resolution? Landscape Urban Plann. 114, 1-8.

Li, X., Zhou, W., Ouyang, Z., Xu, W., Zheng, H., 2012. Spatial pattern of greenspace affects land surface temperature: evidence from the heavily urbanized Beijing metropolitan area, China. Landscape Ecol. 27, 887-898.

Lillesand, T.M., Kiefer, R.W., Chipman, J.W., 2004. Remote Sensing and Image Interpretation. John Wiley \& Sons Ltd., Chichester, UK.

McGarigal, K., Cushman, S.A., Neel, M.C., Ene, E., 2002. FRAGSTATS: Spatial Pattern Analysis Program for Categorical Maps. University of Massachusetts, Amherst MA (Computer software program produced by the authors at the University of Massachusetts)

Miller, M.D., 2012. The impacts of Atlanta's urban sprawl on forest cover and fragmentation. Appl. Geogr. 34, 171-179. 
Nowak, D.J., Crane, D.E., Stevens, J.C., 2006. Air pollution removal by urban trees and shrubs in the United States. Urban For. Urban Green. 4, 115-123.

Nowak, D.J., Hirabayashi, S., Bodine, A., Greenfield, E., 2014. Tree and forest effects on air quality and human health in the United States. Environ. Pollut. 193, 119-129.

Portillo-Quintero, C.A., Sanchez, A.M., Valbuena, C.A., Gonzalez, Y.Y., Larreal, J.T., 2012. Forest cover and deforestation patterns in the Northern Andes (Lake Maracaibo Basin): a synoptic assessment using MODIS and Landsat imagery. Appl. Geogr. 35, 152-163.

Seto, K.C., Woodcock, C.E., Song, C., Huang, X., Lu, J., Kaufmann, R.K., 2002. Monitoring land-use change in the Pearl River Delta using Landsat TM. Int. J. Remote Sens. 23, 1985-2004.

Shandas, V., Alberti, M., 2009. Exploring the role of vegetation fragmentation on aquatic conditions: linking upland with riparian areas in Puget Sound lowland streams. Landscape Urban Plann. 90, 66-75.

Strohbach, M.W., Lerman, S.B., Warren, P.S., 2013. Are small greening areas enhancing bird diversity? Insights from community-driven greening projects in Boston. Landscape Urban Plann. 114, 69-79.

Sun, X., Sun, Q. Zhou, X., Li, X., Yang, M., Yu, A., Geng, F, 2014. Heat wave impact on mortality in Pudong New Area, China in 2013. Sci. Total Environ. 493, 789-794.

Van Den Hoek, J., Ozdogan, M., Burnicki, A., Zhu, A.X., 2014. Evaluating forest policy implementation effectiveness with a cross-scale remote sensing analysis in a priority conservation area of Southwest China. Appl. Geogr. 47, 177-189.

Xu, X., Duan, X., Sun, H., Sun, Q., 2011. Green space changes and planning in the capital region of China. Environ. Manage. 47, 456-467.
Yang, J., McBride, J., Zhou, J., Sun, Z., 2005. The urban forest in Beijing and its role in air pollution reduction. Urban For. Urban Green. 3, 65-78.

Yu, S., Bian, L., Lin, X., 2005. Changes in the spatial scale of Beijing UHI and urban development. Sci. China, Ser. D 48.

Yuan, F., Sawaya, K.E., Loeffelholz, B.C., Bauer, M.E., 2005. Land cover classification and change analysis of the Twin Cities (Minnesota) metropolitan area by multitemporal Landsat remote sensing. Remote Sens. Environ. 98, 317-328.

Zhou, W., Huang, G., Cadenasso, M.L., 2011a. Does spatial configuration matter? Understanding the effects of land cover pattern on land surface temperature in urban landscapes. Landscape Urban Plann. 102, 54-63.

Zhou, W., Huang, G., Pickett, S.T.A., Cadenasso, M.L., 2011b. 90 years of forest cover change in an urbanizing watershed: spatial and temporal dynamics. Landscape Ecol. 26, 645-659.

Zhou, W., Qian, Y., Li, X., et al., 2014. Relationships between land cover and the surface urban heat island: seasonal variability and effects of spatial and thematic resolution of land cover data on predicting land surface temperatures[J]. Landscape Ecol. 29 (1), 153-167.

Zhou, W., Troy, A., 2009. Development of an object-based framework for classifying and inventorying human-dominated forest ecosystems. Int. J. Remote Sens. 30 6343-6360

Zhou, X., Wang, Y., 2011. Spatial-temporal dynamics of urban green space in response to rapid urbanization and greening policies. Landscape Urban Plann. $100,268-277$ 